\title{
Role of High Resolution Ultrasonography and Guided Fine Needle Aspiration Cytology in the Evaluation of Patients with Thyroid Swellings
}

Authors

\author{
Dr Rajmohan J L*, Dr Minimol K L, Dr Nizarudeen A \\ Government Medical College, Thiruvananthapuram \\ Corresponding Author \\ *Dr Rajmohan J L \\ Divine Gardens, Kanakanagar, House No A143 (b) \\ Kowdiar P O, Thiruvananthapuram- 695003, Kerala, India \\ Email: rajmohanjl@yahoo.co.in
}

\begin{abstract}
Introduction: Thyroid swellings constitute a major proportion of neck swellings. Approach to the management of solitary and multinodular thyroid differs, and conservative management is considered to be the preferred treatment option. The utilization of high-frequency ultrasound to augment clinical diagnosis would be helpful in avoiding unnecessary thyroidectomy in a patient presented with nodular thyroid disease.

Materials and Method: This study was carried out in the department of surgery, Medical College, Trivandrum during 2009 to 2012. We evaluated the role of high resolution ultrasound and FNAC in thyroid swelling in 50 patients. Sensitivity, specificity, true positive predictive value and negative predictive value and accuracy of sonological findings compared to FNAC findings were calculated.

Results: There was a female predominance with male to female ratio of 1:9. Although clinical evaluation showed most of the cases as solitary nodules, sonological examination and fine needle aspiration cytology proved that the most common type was multinodular goiter followed by adenoma. In the present study sonological diagnosis failed to identify malignancy in all cases but was proven by FNAC.

Discussion: Major challenges faced by a clinician in management of thyroid swelling is, whether the nodule is benign or malignant and whether management need to be conservative or surgical. In our study group, a marked discrepancy was found between palpatory findings of solitary nodule and sonographic findings. There was also a marked discrepancy between palpatory finding of diffuse enlargement and sonographic findings. Multi nodulargoitre was found to be the most common abnormality. Although 24 patients were diagnosed as having solitary nodule on clinical evaluation ultrasonography showed 14 had solitary nodule while 10 patients had multiple nodules. Out of all 7 cases categorized as malignant in FNAC, all were reported as benign in ultrasound.
\end{abstract}

\section{Introduction}

Thyroid swellings constitute a major proportion of neck swellings seen in our country ${ }^{(1)}$. Even though thyroid gland is situated superficially, which makes it ideal for clinical examination; findings are generally considered unreliable both 


\section{JMSCR Vol||05||Issue||03||Page 19038-19043||March}

in detection of thyroid nodules and assessment of thyroid gland size, especially when the nodules are small ${ }^{(2)}$. High resolution real time sonography allows excellent visualization of the thyroid parenchyma ${ }^{(3)(4)}$. It can pick up filled cysts up to 1 $\mathrm{mm}$ in size and solid nodules up to 2 to $3 \mathrm{~mm}$ in size. This makes sonography one of the most sensitive imaging modalities in detection of thyroid swellings ${ }^{(5,6)}$.

It is common to encounter palpable thyroid nodule in $0.8-1.5 \%$ of men and $5.3-6.4 \%$ of women in clinical practice $^{(7,8)}$. On further work up, most of these nodules turn out to be benign in nature; the various causes being solitary nodules are thyroid adenomas, cysts, thyroiditis ${ }^{(9)}$.

In most centers, the approach to solitary and multiple nodules differs. Conservative management is considered to be the preferred treatment option in these groups of patients so that an unnecessary surgery could be obviated (10)(11). Clinical approach to multiple nodules is more conservative in most centers including ours; we are of the view that high resolution sonography being a sensitive method for detection of thyroid nodularity can significantly alter the approach to patient management, making the strategy more conservative and sparing some patients an operation.

There are sonological criteria suggested by many investigators that attempt to differentiate between benign and malignant conditions in the case of a clinically detected lesion. However, there is no reliable sonological sign to distinguish benign swelling from malignant. This makes further work in the role of high resolution ultrasonography of various thyroid lesions imperative. We evaluated the usefulness of high resolution ultrasonography in thyroid swellings by comparing clinical and sonological findings and comparing it with ultrasound guided FNAC results in our hospital.

Importance of this study lies in the utilization of high-frequency ultrasound to augment clinical diagnosis so that unnecessary thyroidectomy could be avoided in a patient presented with nodular thyroid disease.

\section{Materials and Methods}

This study was carried out in the Department of Surgery, Govt. Medical College, Thiruvananthapuram during 2009 to 2012. We evaluated the role of high resolution ultrasound in thyroid swelling in 50 patients. Permission from the institutional ethics committee was taken before starting the study and as a clinical addition; we conducted the study conforming to the declaration of Helsinki. Moreover, patient confidentiality was maintained strictly. Informed consents were taken from all patients willing to take part in the study. All patients with thyroid swellings were eligible for recruitment to the study. We selected only patients over the age of thirteen. Patients with history of previous thyroidectomy or any neck operation was excluded from the study. We recruited 50 consecutive patients with thyroid swelling as defined by WHO criteria.

\section{Ultrasound characteristics studied included:}

1. Diffuse enlargement or nodular enlargement

2. Number of nodules: solitary or multiple

3. Characteristics of the nodules.

a. Echogenicity: hyperechoic, hypoechoic, isoechoic, anechoic or mixed. b. Margins : well defined or poorly defined.

c. Perinodular halo : complete, incomplete

d. Secondary changes : calcification, hemorrhage

e. Type of calcification: micro/macrocalcification

4. Cervical lymph nodes

5. Colour flow pattern 
During the scan, the patient was put in supine and neck hyper extended position. Acoustic jelly was applied to the skin as a coupling agent. The scan was performed in sagittal, transverse and oblique planes. Imaging of the lower pole of thyroid was improved by asking the patient to swallow. For colour Doppler studies, the color sensitivity was optimized by raising the color gain to just below the threshold of colour noise. Fine needle aspiration was performed after explaining the procedure to the patient and after taking an informed consent. The area was cleaned with povidone iodine solution. A 22-gauge needle and a $10 \mathrm{ml}$ syringe were used for suction. In nodules showing cystic changes, fine needle aspiration was obtained from the solid area of the nodule. In multinodulargoitre, fine needle aspiration cytology was obtained from either a suspicious nodule (poorly defined margins, hypoechogenicity) or from the largest representative nodule. After localizing the lesion, the needle was introduced tangential to the probe at the selected depth. In cases in which FNA results were indeterminate or showed inadequate material a repeat FNA was obtained. None of the 50 patients suffered any complication after FNAC, except pain.

Using a pre-tested case report form, basic demographic data, fine needle aspiration cytology findings and clinical symptoms were collected by the principal investigator with help of residents. Consequently, the data were entered into an excel database with proper precaution taken to safeguard against data entry errors. All statistical analyses were carried out in SPSS and R. Baseline demographic data were summarized with mean and standard deviation or median and interquartile range (IQR) depending on the nature of distribution of the variables. Categorical data were summarized with number and percentages. Sensitivity, specificity, true positive predictive value and negative predictive value and accuracy of sonological findings compared to fine needle aspiration cytology findings were calculated.
Table1: Baseline characteristics.

\begin{tabular}{|c|c|}
\hline & Overall \\
\hline $\mathrm{n}$ & 50 \\
\hline Age.in.years (mean (sd)) & $39.54(13.65)$ \\
\hline Sex $=$ male/female $(\%)$ & $5 / 45(10.0 / 90.0)$ \\
\hline \multicolumn{2}{|l|}{ Symptom (\%) } \\
\hline MultinodularGoitre & $39(78.0)$ \\
\hline Solitary nodule & $6(12.0)$ \\
\hline Diffuse Goitre & $3(6.0)$ \\
\hline Malignancy & $1(2.0)$ \\
\hline Thyroiditis & $1(2.0)$ \\
\hline \multicolumn{2}{|l|}{ Clinical.Diagnosis (\%) } \\
\hline MultinodularGoitre & $15(30.0)$ \\
\hline Solitary nodule & $24(48.0)$ \\
\hline Diffuse Goitre & $6(12.0)$ \\
\hline Malignancy & $3(6.0)$ \\
\hline Thyroiditis & $2(4.0)$ \\
\hline $\begin{array}{l}\text { Nature.of.lesion } \\
\text { lesion/Malignancy }(\%)\end{array}=\quad$ Benign & $45 / 5(90.0 / 10.0)$ \\
\hline \multicolumn{2}{|l|}{ Sonological.diagnosis (\%) } \\
\hline MultinodularGoitre & $28(56.0)$ \\
\hline Adenoma & $12(24.0)$ \\
\hline Diffuse enlargement & $6(12.0)$ \\
\hline Malignancy & $4(8.0)$ \\
\hline \multicolumn{2}{|l|}{ FNAC (\%) } \\
\hline MultinodularGoitre & $26(52.0)$ \\
\hline Adenoma- Solitary & $7(14.0)$ \\
\hline Adenomatous nodule -solitary & $5(10.0)$ \\
\hline Diffuse hyperplasia & $3(6.0)$ \\
\hline Thyroiditis & $3(6.0)$ \\
\hline Malignancy & $5(10.0)$ \\
\hline MultinodularGoitre with TB & $1(2.0)$ \\
\hline
\end{tabular}

Figure 1: presentation of thyroid

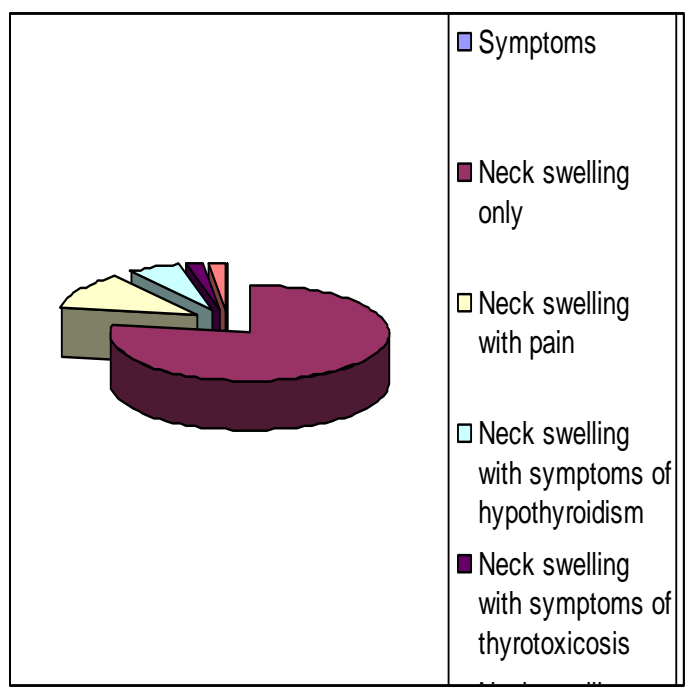




\section{JMSCR Vol||05||Issue||03||Page 19038-19043||March}

Table 2

\begin{tabular}{|c|c|c|c|c|c|c|}
\hline Var & [ALL] $\mathrm{N}=50$ & Adenoma $\mathrm{N}=12$ & $\begin{array}{c}\text { Diffuse } \\
\text { enlargemen } \\
\text { t N=6 }\end{array}$ & $\begin{array}{c}\text { Malignancy } \\
\mathrm{N}=4\end{array}$ & $\begin{array}{l}\text { Multinodular } \\
\text { Goitre } N=28\end{array}$ & p.overall \\
\hline Age.in.years & 39.5 (13.6) & $41.9(14.2)$ & $24.0(13.3)$ & $46.2(7.14)$ & $40.9(12.4)$ & 0.020 \\
\hline Sex: & & & & & & 0.101 \\
\hline female & $45(90.0 \%)$ & $11(91.7 \%)$ & $6(100 \%)$ & $2(50.0 \%)$ & $26(92.9 \%)$ & \\
\hline male & $5(10.0 \%)$ & $1(8.33 \%)$ & $0(0.00 \%)$ & $2(50.0 \%)$ & $2(7.14 \%)$ & \\
\hline Symptom: & & & & & & 0.004 \\
\hline Diffuse Goitre & $3(6.00 \%)$ & $0(0.00 \%)$ & $2(33.3 \%)$ & $1(25.0 \%)$ & $0(0.00 \%)$ & \\
\hline Malignancy & $1(2.00 \%)$ & $0(0.00 \%)$ & $0(0.00 \%)$ & $0(0.00 \%)$ & $1(3.57 \%)$ & \\
\hline MultinodularGoitre & $39(78.0 \%)$ & $10(83.3 \%)$ & $2(33.3 \%)$ & $2(50.0 \%)$ & $25(89.3 \%)$ & \\
\hline Solitary nodule & $6(12.0 \%)$ & $2(16.7 \%)$ & $2(33.3 \%)$ & $0(0.00 \%)$ & $2(7.14 \%)$ & \\
\hline Thyroiditis & $1(2.00 \%)$ & $0(0.00 \%)$ & $0(0.00 \%)$ & $1(25.0 \%)$ & $0(0.00 \%)$ & \\
\hline Clinical.Diagnosis: & & & & & & $<0.001$ \\
\hline Diffuse Goitre & $6(12.0 \%)$ & $0(0.00 \%)$ & $4(66.7 \%)$ & $0(0.00 \%)$ & $2(7.14 \%)$ & \\
\hline Malignancy & $3(6.00 \%)$ & $0(0.00 \%)$ & $0(0.00 \%)$ & $3(75.0 \%)$ & $0(0.00 \%)$ & \\
\hline MultinodularGoitre & $15(30.0 \%)$ & $0(0.00 \%)$ & $0(0.00 \%)$ & $0(0.00 \%)$ & $15(53.6 \%)$ & \\
\hline Solitary nodule & $24(48.0 \%)$ & $12(100 \%)$ & $0(0.00 \%)$ & $1(25.0 \%)$ & $11(39.3 \%)$ & \\
\hline Thyroiditis & $2(4.00 \%)$ & $0(0.00 \%)$ & $2(33.3 \%)$ & $0(0.00 \%)$ & $0(0.00 \%)$ & \\
\hline Nature.of.lesion: & & & & & & $<0.001$ \\
\hline Benign lesion & $45(90.0 \%)$ & $12(100 \%)$ & $6(100 \%)$ & $0(0.00 \%)$ & $27(96.4 \%)$ & \\
\hline Malignancy & $5(10.0 \%)$ & $0(0.00 \%)$ & $0(0.00 \%)$ & $4(100 \%)$ & $1(3.57 \%)$ & \\
\hline Sonological.diagnosis: & & & & & & $<0.001$ \\
\hline Adenoma & $12(24.0 \%)$ & $12(100 \%)$ & $0(0.00 \%)$ & $0(0.00 \%)$ & $0(0.00 \%)$ & \\
\hline Diffuse enlargement & $6(12.0 \%)$ & $0(0.00 \%)$ & $6(100 \%)$ & $0(0.00 \%)$ & $0(0.00 \%)$ & \\
\hline Malignancy & $4(8.00 \%)$ & $0(0.00 \%)$ & $0(0.00 \%)$ & $4(100 \%)$ & $0(0.00 \%)$ & \\
\hline MultinodularGoitre & $28(56.0 \%)$ & $0(0.00 \%)$ & $0(0.00 \%)$ & $0(0.00 \%)$ & $28(100 \%)$ & \\
\hline FNAC: & & & & & & $<0.001$ \\
\hline Adenoma- Solitary & $7(14.0 \%)$ & $7(58.3 \%)$ & $0(0.00 \%)$ & $0(0.00 \%)$ & $0(0.00 \%)$ & \\
\hline $\begin{array}{l}\text { Adenomatous } \\
\text { nodule -solitary }\end{array}$ & $5(10.0 \%)$ & $5(41.7 \%)$ & $0(0.00 \%)$ & $0(0.00 \%)$ & $0(0.00 \%)$ & \\
\hline Diffuse hyperplasia & $3(6.00 \%)$ & $0(0.00 \%)$ & $3(50.0 \%)$ & $0(0.00 \%)$ & $0(0.00 \%)$ & \\
\hline Malignancy & $5(10.0 \%)$ & $0(0.00 \%)$ & $0(0.00 \%)$ & $4(100 \%)$ & $1(3.57 \%)$ & \\
\hline MultinodularGoitre & $26(52.0 \%)$ & $0(0.00 \%)$ & $0(0.00 \%)$ & $0(0.00 \%)$ & $26(92.9 \%)$ & \\
\hline $\begin{array}{l}\text { MultinodularGoitre } \\
\text { with TB }\end{array}$ & $1(2.00 \%)$ & $0(0.00 \%)$ & $0(0.00 \%)$ & $0(0.00 \%)$ & $1(3.57 \%)$ & \\
\hline Thyroiditis & $3(6.00 \%)$ & $0(0.00 \%)$ & $3(50.0 \%)$ & $0(0.00 \%)$ & $0(0.00 \%)$ & \\
\hline
\end{tabular}

diffuse enlargement one (16.6\%) had a solitary

\section{Results}

A total of 50 patients underwent sonological examination apart from clinical examinations and fine needle aspiration cytology as part of this study. There were 45 females and five males. There was a female predominance with male to female ratio of 1:9. In the present study, most of the cases were clinically diagnosed as solitary nodule, followed by Multinodular goiter. On sonological examination, the most common type was multinodular goiter, followed by adenoma. On fine needle aspiration cytology, the same pattern was observed. The details regarding the baseline characteristics are given in table1. Sonologically, 45(90\% were benign and the rest malignant.

Of the 24 patients with solitary nodules on clinical evaluation, only 14 patients $(58.3 \%)$ had a solitary lesion while 10 patients $(41.6 \%)$ had multiple nodules after sonography. In the 6 patients with nodule, and another had multiple nodules (16.6\%) sonologicaly. 4 cases of multinodulargoitre showed one or more poorly defined nodules. Of these four cases, one was found to be carcinoma in multinodulargoitre on fine needle aspiration cytology; which was confirmed by histopathology after surgery. This case had macrocalcification but no microcalcification. The incidence of malignancy in multinodulargoitre in our study was $3.8 \%$.

Sonological diagnosis failed to identify malignancy in all cases. Malignancy was proven by fine needle aspiration cytology. Sonological diagnosis in these patients reported as adenoma in all cases. Ultrasound accurately picked up 39 cases as benign and misdiagnosed 4 as malignant out of 43 cases categorized as benign by fine needle aspiration cytology. However, out of all 7 cases categorized as malignant in FNAC, all were reported as benign in ultrasound. The sensitivity 
of ultrasound in differentiating between benign and malignant was 0.91 and specificity was 0 in this study (table 2)

$\begin{array}{lc}\text { Apparent prevalence } & 0.92(0.81,0.98) \\ \text { True prevalence } & 0.86(0.73,0.94) \\ \text { Sensitivity } & 0.91(0.78,0.97) \\ \text { Specificity } & 0.00(0.00,0.53) \\ \text { Positive predictive value } & 0.85(0.71,0.94) \\ \text { Negative predictive value } & 0.00(0.00,0.72) \\ \text { Positive likelihood ratio } & 0.91(0.82,1.00)\end{array}$

The sensitivity of clinical diagnosis was only 51 percent $(0.36,0.66)$ and specificity0.40 (0.05, $0.85)$

\section{Discussion}

A major challenge faced by a clinician is to determine whether a thyroid nodule is benign or malignant. Although certain aspects of history and physical examination may suggest malignancy, in most cases, these are nonspecific and are of no predictive value. Against this background, we undertook this study to evaluate the ultrasound as a diagnostic tool to differentiate between benign and malignant diseases in patients presented with thyroid swellings in outpatient settings. Our study has shown that soft-tissue ultrasound has more than 90 percent sensitivity in detecting benign swelling.

In our study, sonological examination could correctly identify 90 percent of benign cases but failed to identify malignant cases when compared to FNAC findings. In this respect, our study contradicts with other studies. In our study, out of 50 patients referred for sonographic evaluation of palpable abnormalities of the thyroid gland, 90 per cent of patients were females and only $10 \%$ were males. This goes with literature that thyroid disorders are more common in females than in males. The mean age of patients was 39.5 years. Thyroid nodules were common in the 3rd and 4th decades of life. Only $6 \%$ patients belong to geriatric age group, among which none had malignancy. In our study group, peak incidence of malignancy was in the 4th decade of life. The youngest patient with thyroid malignancy was aged 31 years and the eldest 55 years. All the 5 cases of malignancy in our study were papillary carcinomas. This is in concordance with literature as papillary carcinomas show two peaks, one in young adults and the other in the elderly. The mean age of patients to present is about 45 years. Of the 5 cases of papillary carcinoma, $40 \%$ were males and $60 \%$ were females. This is in concordance with literature as females are more commonly affected than males. Our study group had 3 cases of thyroiditis (6\%). The mean age of patients with thyroiditis in our study group was 25 years.

In our study group, a marked discrepancy was found between palpatory findings of solitary nodule and sonographic findings. There was also a marked discrepancy between palpatory finding of diffuse enlargement and sonographic findings. The reliability of clinical examination, particularly concerning solitary nodules has been established by many investigators. In the series of Brander et al, only one-third of the solitary nodules proved to be solitary by ultrasound evaluation ${ }^{(11)}$. Of the 77 separate nodules, they found 43 had escaped detection by clinical examination. Based on this finding they suggested that the greatest benefit of ultrasonography is in assumed solitary nodules. In the study by Knudsen et al $50 \%$ of clinically diagnosed solitary nodule were later proven to be multiple nodules after sonological evaluation validation of ultrasonography of the thyroid gland for epidemiological purposes ${ }^{(12)}$. They found that multiple nodules are frequently overlooked clinically. Scheible et al found $40 \%$ of palpatory solitary nodules as multinodular on ultrasound examination and Walker et al noticed multinodularity in $20 \%$ of their series of 266 consecutive clinically solitary nodules ${ }^{(13)}$. Hence literature agrees with our finding of discrepancy between palpatory and sonographic finding. The most common abnormality of thyroid seen in our study was multinodular goiter (54\%). This is in accordance to literature. Multinodulargoitre was more common in females. The nodules were hypoechoic in $14.8 \%$ of cases, hyperechoic in 


\section{JMSCR Vol||05||Issue||03||Page 19038-19043||March}

$37 \%$ cases and isoechoic in $48.1 \%$ of cases. Solbiati et al reported that typically hyperplastic nodule is isoechoic to the gland in the majority of the cases ${ }^{(4)}$. We found isoechoic echo texture as the most common echo pattern in our study group of 50 patients.

\section{Reference}

1. Unnikrishnan AG, Menon UV. Thyroid disorders in India: An epidemiological perspective. Indian journal of endocrinology and metabolism. 2011;15(Supp12): S78-S81.

2. Brander A, Viikinkoski P, Tuuhea J, Voutilainen L, Kivisaari L. Clinical versus ultrasound examination of the thyroid gland in common clinical practice. Journal of Clinical Ultrasound. 1992;20(1):37-42.

3. Cole-Beuglet C, Goldberg BB. New highresolution ultrasound evaluation of diseases of the thyroid gland: A review article. JAMA : the journal of the American Medical Association. 1983;249 (21):2941-4.

4. Solbiati L, Volterrani L, Rizzatto G, Bazzocchi M, Busilacci P, Candiani F, et al. The thyroid gland with low uptake lesions: evaluation by ultrasound. Radiology. 1985;155(1):187-91.

5. Butch RJ, Simeone JF, Mueller PR. Thyroid and parathyroid ultrasonography. Radiologic clinics of North America. 1985;23(1):57-71.

6. Xie C, Cox P, Taylor N, LaPorte S. Ultrasonography of thyroid nodules: a pictorial review. Insights into Imaging. 2016;7(1):77-86.

7. Tunbridge WM, Evered DC, Hall R, Appleton D, Brewis M, Clark F, et al. The spectrum of thyroid disease in a community: the Whickham survey. Clinical endocrinology. 1977;7(6):481-93.

8. Vander JB, Gaston EA, Dawber TR. Significance of solitary nontoxic thyroid nodules; preliminary report. The New England journal of medicine. 1954; 251 (24):970-3.

9. Filetti S, Durante C, Torlontano M. Nonsurgical approaches to the management of thyroid nodules. Nat Clin Pract End Met. 2006;2(7):384-94.

10. Burch HB. Evaluation and management of the solid thyroid nodule. Endocrinology and metabolism clinics of North America. 1995;24(4):663-710.

11. Brander A, Viikinkoski P, Tuuhea J, Voutilainen L, Kivisaari L. Clinical versus ultrasound examination of the thyroid gland in common clinical practice. J Clin Ultrasound. 1992;20(1):37-42.

12. Knudsen N, Bols B, Bulow I, Jorgensen T, Perrild $\mathrm{H}$, Ovesen $\mathrm{L}$, et al. Validation of ultrasonography of the thyroid gland for epidemiological purposes. Thyroid. 1999;9 (11):1069-74.

13. Scheible W, Leopold GR, Woo VL, Gosink BB. High-resolution real-time ultrasonography of thyroid nodules. Radiology. 1979;133(2):413-7. 